\title{
The Research on Running Characteristics of A New Type of Radiant Air Conditioning Combined with Fresh Air System
}

\author{
Yingning $\mathrm{Hu}^{1, \mathrm{a}}$, Xuan $\mathrm{YaO}^{2, \mathrm{~b}}$, Weiming Zhong ${ }_{\mathrm{e}}^{3, \mathrm{c}}$, Yan $\mathrm{Wang}^{4, \mathrm{~d}}$ Shanshan $\mathrm{Hu}^{5}$, \\ ${ }^{1}$ School of Guangxi University, Nanning 530004, China. \\ ${ }^{2}$ School of Guangxi University, Nanning 530004, China. \\ ahyn@gxu.edu.cn, ${ }^{b}$ missailisi@126.com, czwm198@126.com, ${ }^{\text {d } 532807271 @ q q . c o m, ~}$ \\ echloee_2000@163.com, ${ }^{\mathrm{f}}$ hcj_2016@163.com
}

Keywords: Radiant air conditioning, Fresh air system, Temperature field, Comfortable, Running performance, Energy-saving

\begin{abstract}
The aim of the article is to comprehensively test and explore the running performance of a new type of radiant air conditioning combined with fresh air system by simulating the climate that summer is hot and winter is warm, which is developed by the laboratory research group. The test results show that, Under the working conditions of refrigerating, heating and dehumidifying, The indoor temperature difference is about $2{ }^{\circ} \mathrm{C}$ in horizontal direction and less than $1{ }^{\circ} \mathrm{C}$ in vertical direction. The temperature distribution is uniform and indoor thermal environment is comfortable. the fresh air system has higher dehumidifying effect so it is able to prevent condensing phenomenon, and the running performance of the system is stable and reliable.
\end{abstract}

\section{Introduction}

With the progress of science and technology and the change of lifestyle, People's Daily life almost spend $80 \%$ time in the room so it has an increasing demand on indoor environment. Radiant air conditioning with comfort, health, environmental protection and energy-saving gets extensive attention and application gradually. Domestic and foreign scholars have studied all aspects in the field of radiation air conditioning.

Corgnati S P et al ${ }^{[1]}$ carried out the numerical simulation experiments by CFD in two conditions of using mixed ventilation system separately and combined with ceiling radiant cooling system together. Results showed radiant system and ventilation system used together would make the indoor air quality more comfortable. Aleksandra et $\mathrm{al}^{[2]}$ put forward when the temperature of supplying air provided by personalized ventilation system was $25{ }^{\circ} \mathrm{C}$ it was beneficial to improve the indoor thermal environment. At the same time personalized ventilation system provided 10 times fresh air than hybrid ventilation system which can improve indoor air quality. Yoshidomi $\mathrm{T}$ et $\mathrm{al}^{[3]}$ assessed the performance of radiant ceiling system on-site. They found that no matter in heating or cooling mode, the indoor temperature difference at $0.1 \mathrm{~m}$ and $1.7 \mathrm{~m}$ in vertical direction was less than $1.5{ }^{\circ} \mathrm{C}$ the level of $0.7 \mathrm{~m}$ in horizontal direction was less than $1.5{ }^{\circ} \mathrm{C}$. At the same time they measured the range of PMV was \pm 0.5 and PPD was less than $10 \%$. De Adana et al ${ }^{[4]}$ predicted the time range for the ceiling radiant cooling system by liquid (water) circulation heating to achieve the set point for thermal comfort in the room with different heat load by experimentation. Moon Keun Kim et $\mathrm{al}^{[5]}$ and Catalin Teodosiu et $\mathrm{al}^{[6]}$ found that the radiant system combined with ventilation system can improve the air dew-point temperature on the ceiling surface, which not only to avoid the risk of condensation but also save energy consumption by numerical simulation and experiment analysis. Oxizidisa $\mathrm{S}$ et $\mathrm{al}^{[7]}$ indicated that according to the indoor temperature to adjust the water temperature and then to control the radiant system, which was able to prevent the damage of air conditioning equipments due to frequently turn on compressor and the waste of energy consumption. Takehito Imanari et $\mathrm{al}^{[8]}$ and Yasin Khan et $\mathrm{al}^{[9]}$ analyzed the energy consumption and thermal comfort between ceiling radiant cooling system and traditional all-air system. Experiments showed 
that the radiant air conditioning system can excellently provide suitable temperature range and uniform temperature distribution and the energy-saving is over $10 \%$ than traditional all-air system.

Most studies about radiant air conditioning system at home and abroad used water as heat exchange medium, its running effect was strongly influenced by supplying water temperature. In this paper, there was a new type of radiant air conditioning combined with fresh air system that temperature and relative humidity can be controlled independently and the fresh air system can dehumidify fresh air before it getting into the room therefore indoor comfortable level was high and more energy efficiency.

\section{Experimental platform}

In this paper, the experimental platform is composed of two rooms, The size of big room is $7.8 \mathrm{~m}$ * $5.8 \mathrm{~m} * 5.8 \mathrm{~m}$ that depend on conventional air conditioning and ultrasonic humidifier to simulate the temperature and humidity of outdoor environment; the size of small room is $4 \mathrm{~m} * 4 \mathrm{~m} * 2.8 \mathrm{~m}$ that install the new type of radiant air conditioning combined with fresh air system.

The new type of radiant air conditioning combined with fresh air system with the rated power of $2.2 \mathrm{KW}$ was consisted of the radiant module and the air system. The whole unit used refrigerant ( R410A) as the medium. The operation schematic diagram of this new radiant air conditioning was shown in figure1.

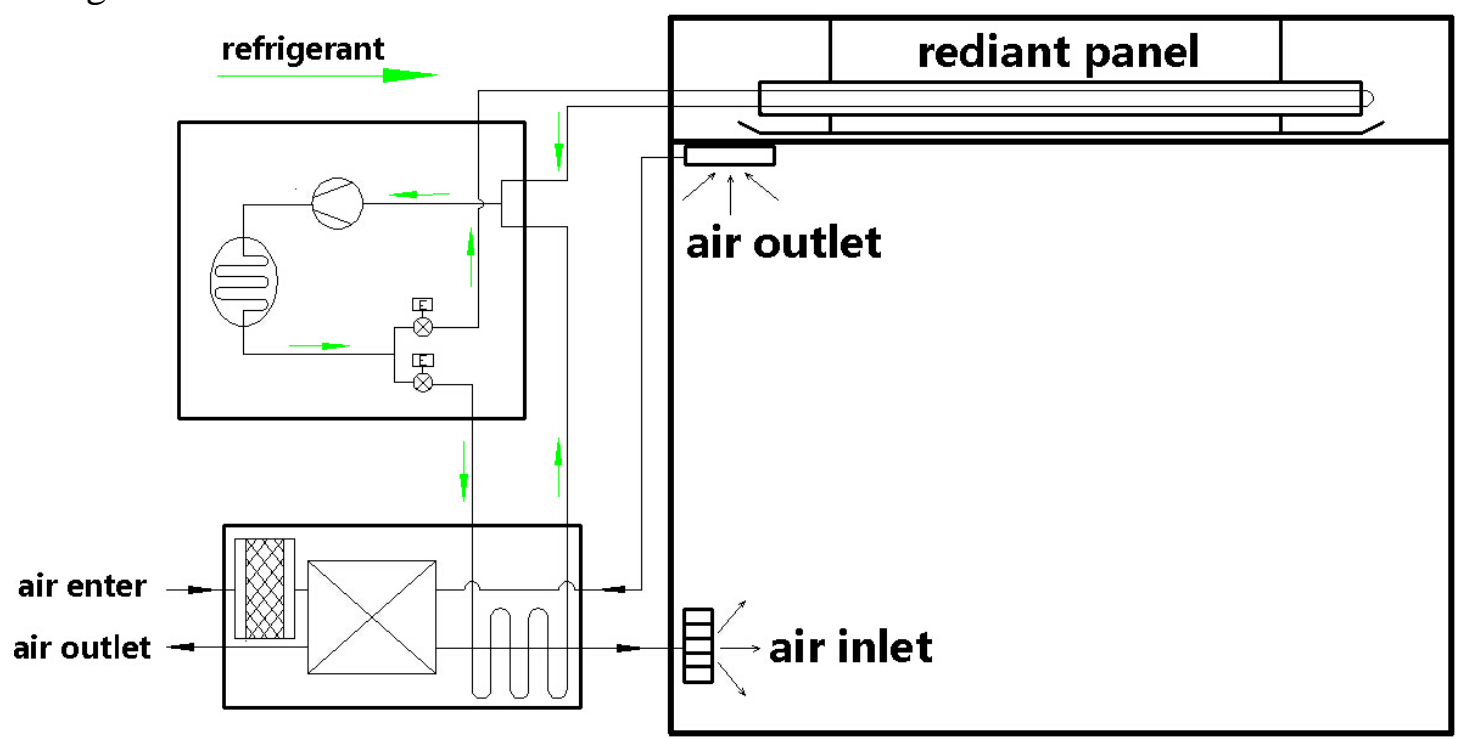

Fig. 1 Operation schematic diagram of the new radiant air conditioning

\section{Experimental design}

This experiment respectively simulated the outdoor temperature and relative humidity of summer, winter, transition seasons and then run the new radiant air conditioning combined with fresh air system in the test room to research the indoor temperature distribution and running performance and dehumidifying efficiency of the system.

On refrigerating and dehumidifying conditions there was extra heat load of 500w in the room, which was equivalent of the total heat load from fluorescent lamp, computer, doors and windows normally.

\section{Result and analysis}

The change of temperature and humidity of indoor environment directly influence the comfortable feeling of people, and low energy consumption is important indicator of economic and environmental. So this article aims at researching indoor temperature field distribution, dehumidifying efficiency of the air system, running performance of system and energy consumption 
under different working conditions.

\section{Refrigeration Condition [simulative ambient: $\mathrm{T}=35{ }^{\circ} \mathrm{C}, \mathrm{RH}=\mathbf{8 0} \%$ ]}

\section{The changing of indoor temperature field}

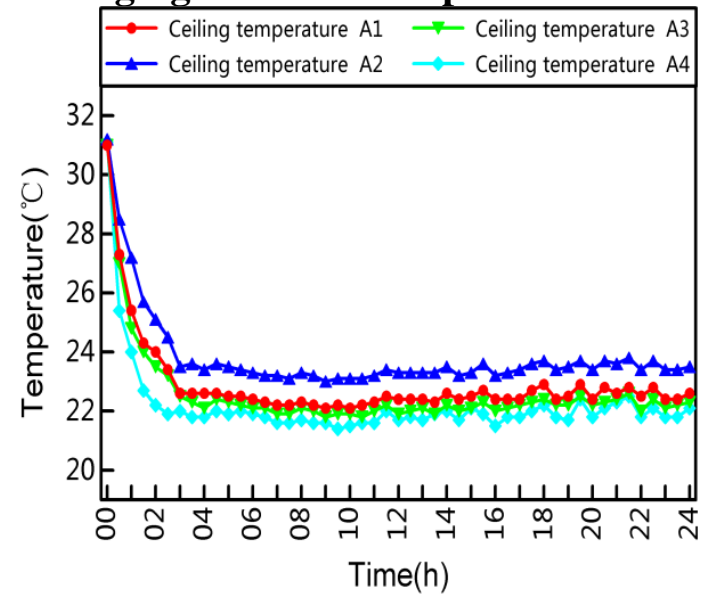

Fig. 2 The ceiling surface temperature

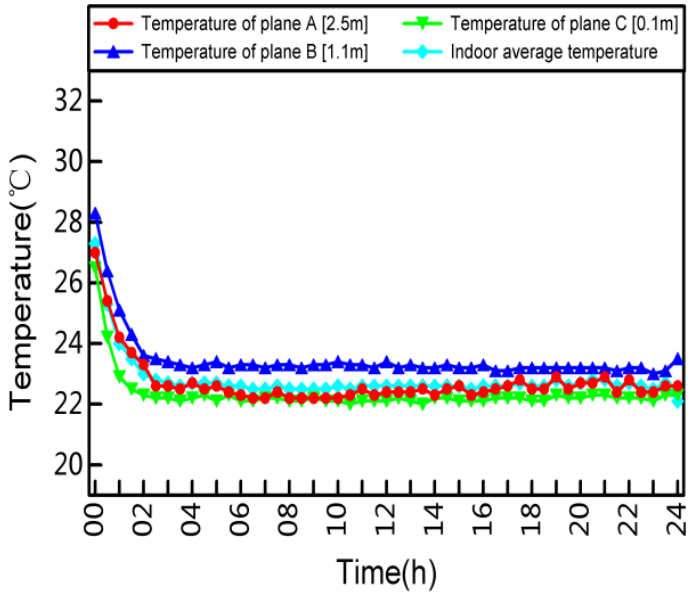

Fig. 3 The vertical temperature

From the figure 2 we can seen that temperature changing trend of tests are consistent and the maximum temperature difference is about $1.8{ }^{\circ} \mathrm{C}$. When achieving steady state the ceiling surface (plane A) temperature basically maintain at $22.2{ }^{\circ} \mathrm{C}$, it is so higher than the dew-point temperature of air that it can prevent condensing phenomenon in the process of refrigerating..

In the figure 3 we found the average temperature of plane $A$, plane $B$ and plane $C$ all fluctuate slightly, the maximum temperature difference is about $1.2{ }^{\circ} \mathrm{C}$ in the vertical direction. After 2.5 hours indoor temperature has dropped from $31.2{ }^{\circ} \mathrm{C}$ to $23{ }^{\circ} \mathrm{C}$, the average cooling rate was fast. Data showed that indoor temperature field distribution is uniform and temperature gradient is small, so the thermal performance of indoor environment is well.

\section{Running performance of the system}

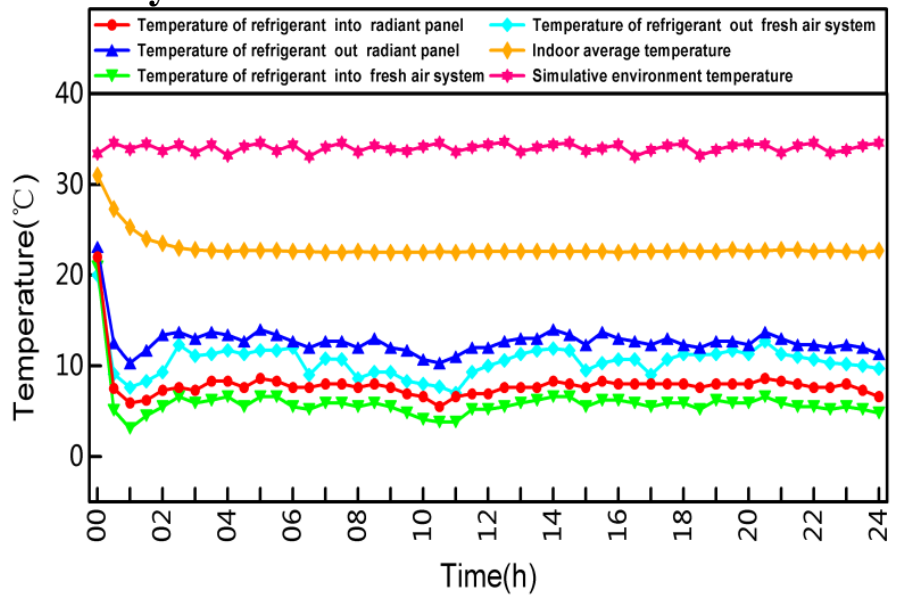

Fig. 4 Running performance of the system

Figure 4 showed the changing trend of refrigerant temperature into/out of radiant panels and the air system are consistent. After 1 hour the running performance achieved stability. Temperature difference of refrigerant into/out of the radiant panel and the air system were $4.9{ }^{\circ} \mathrm{C}$ and $4.6{ }^{\circ} \mathrm{C}$. By the effect of simulative environment, the temperature fluctuations of the refrigerant into/out of air system is slightly bigger than the refrigerant into/out radiant panel. But the maximum swings was below $2.5{ }^{\circ} \mathrm{C}$, which showed that refrigerant conducted on thermal cycling effectively and the running performance of unit is stable, reliable and efficient. 


\section{Heating Condition [simulative ambient: $\mathrm{T}=5{ }^{\circ} \mathrm{C}, \mathrm{RH}=70 \%$ ]}

\section{The changing of indoor temperature field}

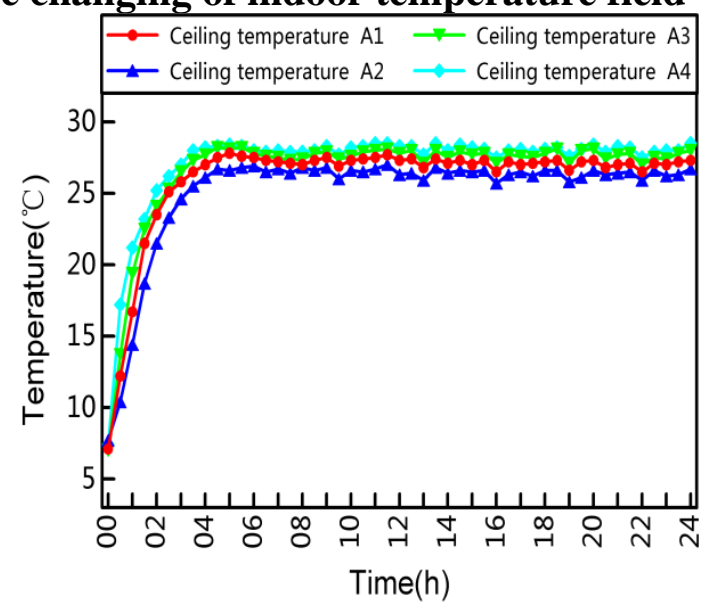

Fig. 5 The ceiling surface temperature

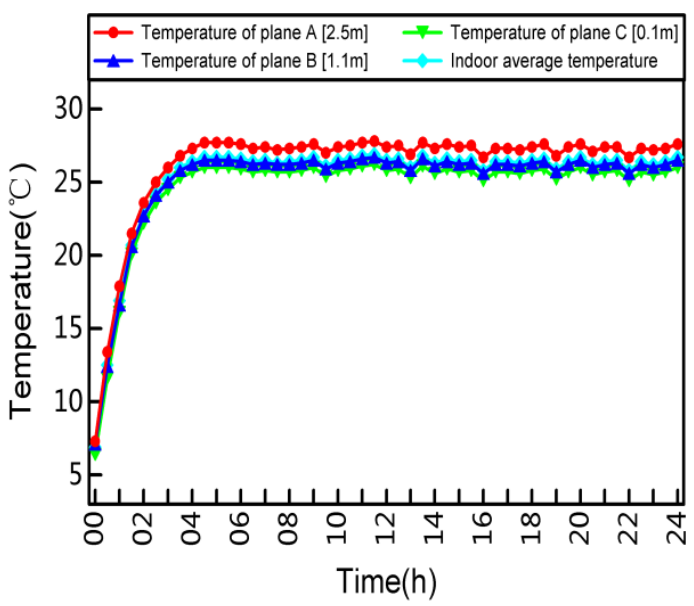

Fig. 6 The vertical temperature

From the figure 5 we can see that all test points are periodically changed with time. The temperature range of ceiling surface was $26.6 \sim 28.2{ }^{\circ} \mathrm{C}$ and the fluctuant amplitude is less than $2{ }^{\circ} \mathrm{C}$.

From the figure 6, in horizontal direction the maximum temperature difference does not exceed $2{ }^{\circ} \mathrm{C}$. Plane $\mathrm{B}$ was equal to near the height of the head when a man sitting in the room and plane $\mathrm{C}$ closed to the height of the ankle. Temperature difference of plane $\mathrm{B}$ and plane $\mathrm{C}$ was minimal so that human body would feel comfortable. After 4 hours the temperature field achieved steady state and the average temperature kept at $25.3{ }^{\circ} \mathrm{C}$ in the room, which meeting the requirements of national standard[GB50736-2012] of comfortable air conditioning. 3.2.2 The running performance of system

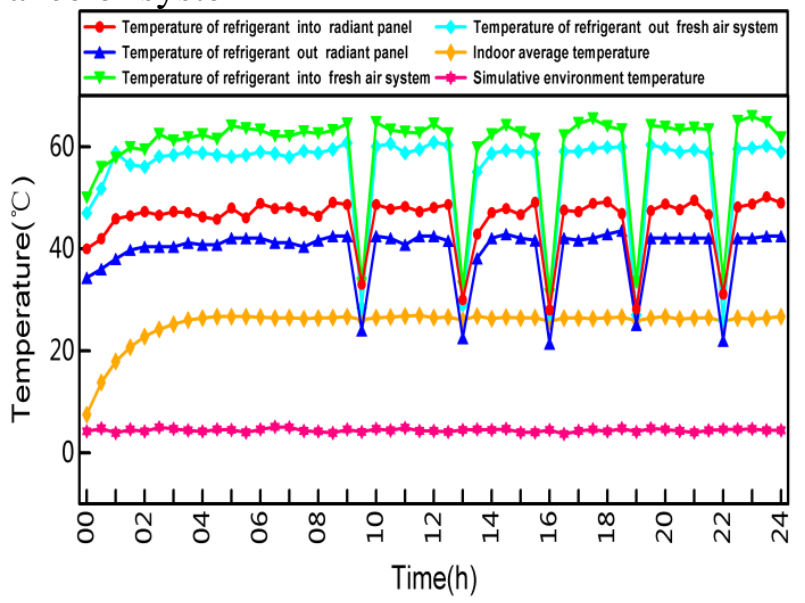

Fig. 7 Running performance of the system

From the figure 7, Temperature difference of refrigerant into/out of the radiant panel and the air system were $15{ }^{\circ} \mathrm{C}$ and $27{ }^{\circ} \mathrm{C}$, heat transfer was large at system terminal. After 9.5 hours, the inverter compressor appeared the reverse circulation phenomenon to defrost and spend 6 minutes on defrosting a time, which effectively protected the heating capacity and prolong the service life of the unit. Inverter control system of the unit is agility and running performance of the system is stable and reliable. 


\section{Dehumidifying Condition [simulative ambient: $\mathrm{T}=2{ }^{\circ} \mathrm{C}, \mathrm{RH}=85 \%$ ]}

\section{The change of Indoor temperature field}

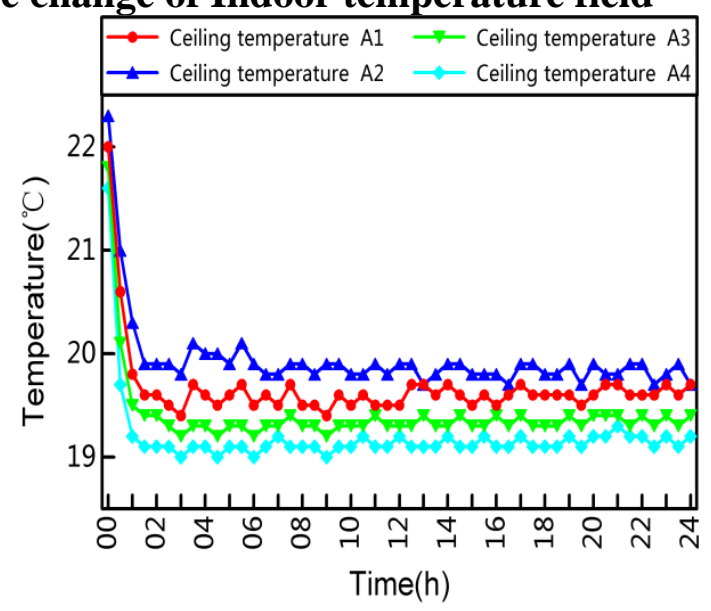

Fig. 8 The ceiling surface temperature

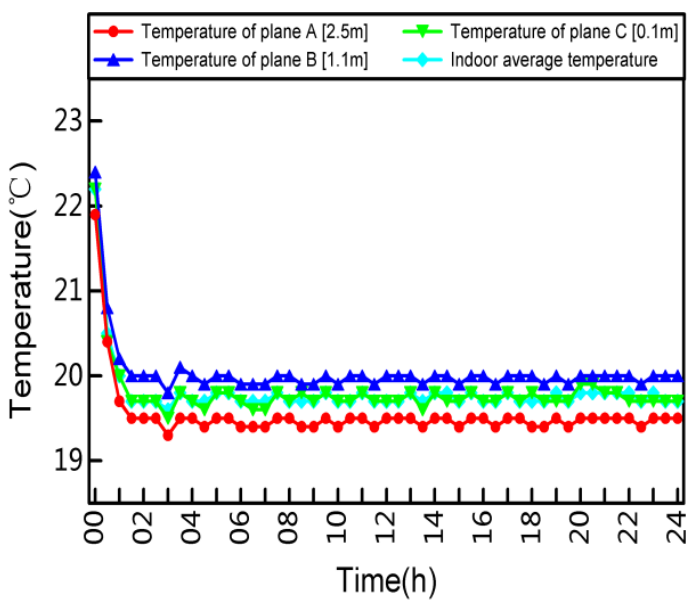

Fig. 9 The vertical temperature

It can be seen from the figure 8 and figure 9 that the temperature curve of ceiling surface waved gently and the maximum temperature difference is about $1{ }^{\circ} \mathrm{C}$. When achieving steady state the ceiling surface temperature is $19.5{ }^{\circ} \mathrm{C}$, it was also higher than the dew-point temperature. Plane $\mathrm{C}$ closed to the floor so it is affected by the temperature of supplying air slightly and the volatility is slightly heavy than plane $\mathrm{B}$. After 1.5 hours, the indoor average temperature achieved $19.8^{\circ} \mathrm{C}$. In the vertical direction the maximum temperature difference was less than $1{ }^{\circ} \mathrm{C}$. The temperature field distribution in the room was very uniform and thermal environment was comfortable.

\section{Dehumidifying efficiency of fresh air system}

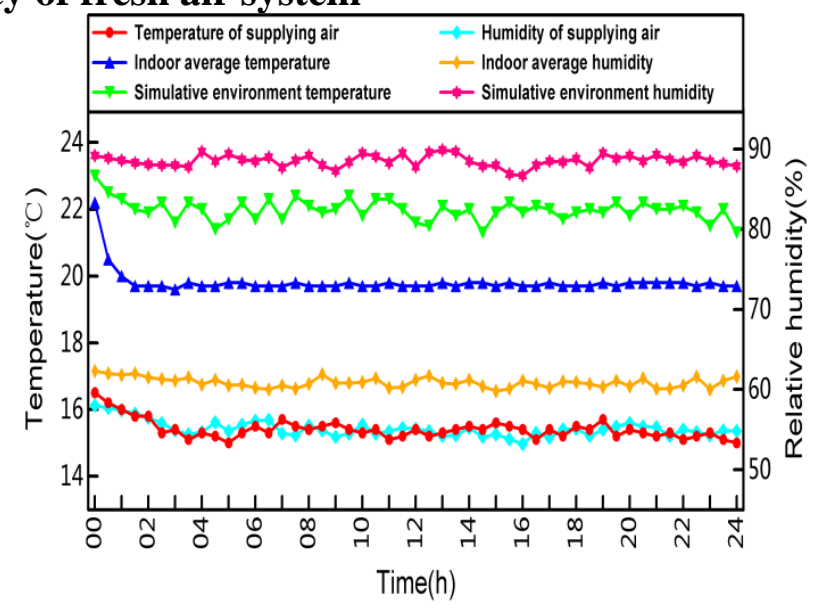

Fig. 10 The change of temperature and relative humidity

Figure 10 showed that the indoor temperature and relative humidity changed with the supplying air temperature and relative humidity. We can get relative humidity ratio of air by checking the enthalpy wet figure, as shown in table 1.

Table 1 Humidity ratio of supplying air, indoor air and outdoor air

\begin{tabular}{cccc}
\hline \multirow{2}{*}{ Name } & $\begin{array}{c}\text { The average } \\
\text { temperature }\left({ }^{\circ} \mathrm{C}\right)\end{array}$ & $\begin{array}{c}\text { The average relative } \\
\text { humidity }(\%)\end{array}$ & $\begin{array}{c}\text { Humidity ratio } \\
(\mathrm{g} / \mathrm{kg} \text { dry air })\end{array}$ \\
\hline supplying air & 15.4 & 55.1 & 6.04 \\
indoor air & 19.8 & 60.9 & 8.86 \\
outdoor air & 22 & 87.5 & 14.71 \\
\hline
\end{tabular}

From table 1 we can see that relatively to outdoor air the dehumidifying quantity of air system is $8.67 \mathrm{~g} / \mathrm{kg}$ and the relative humidity is $60.9 \%$ in the room, which meet the requirements of national standard [GB50736-2012] of comfortable air conditioning. The dehumidifying capacity of air system is great. 


\section{Power consumption of the system}

The power consumption of air conditioning is the important indicator on energy-efficient of building and how to reduce the power consumption is always the development proposition in the field of HVAC.

In this experiment, after running the system on 24 hours under the working conditions of refrigerating, heating and dehumidifying respectively the power consumption is 11.9, 10.1, 8.7 KWh. The power consumption of refrigeration condition is highest and dehumidifying condition is minimum. If used a conventional air conditioning in the same room and the EER (energy efficiency ratio) of unit in cooling mode is 3, we can calculate the power consumption is $20.4 \mathrm{KWh}$. The new radiant air conditioning system was energy-saving $42 \%$ than a conventional air conditioning.

\section{Conclusion}

1) The indoor temperature were $23{ }^{\circ} \mathrm{C}, 25.3{ }^{\circ} \mathrm{C}$ and $25.3{ }^{\circ} \mathrm{C}$ respectively on the working conditions of refrigerating, heating and dehumidifying. The maximum temperature difference in the room all less than $2{ }^{\circ} \mathrm{C}$, the temperature field distribution was uniform and the indoor thermal environment was comfortable.

2) On the working conditions of refrigerating and dehumidifying, the ceiling temperature was much higher than the dew-point temperature of air and the air system can prevent condensing phenomenon.

3) Temperature difference of refrigerant into/out of the radiant panel and the air system remained stable, refrigerant conducted on thermal cycling effectively and the running performance of unit is stable, reliable and efficient.

4) On the working conditions of refrigerating, heating and dehumidifying respectively the power consumption is $11.9 \mathrm{KWh}, 10.1 \mathrm{KWh}, 8.7 \mathrm{KWh}$.

With the same conditions the new radiant air conditioning combined with fresh air system was energy-saving $42 \%$ than a conventional air conditioning.

\section{Reference}

[1] Corgnati S P, Perino M, Fracastoro G V, et al. Experimental and numerical analysis of air and radiant cooling systems in offices[J]. Building and Environment, 2008,44(4).

[2] Lipczynska A, Kaczmarczyk J, Melikov A K. Thermal environment and air quality in office with personalized ventilation combined with chilled ceiling[J]. Building and Environment, 2015,92:603-614.

[3] Li R, Yoshidomi T, Ooka R, et al. Field evaluation of performance of radiant heating/cooling ceiling panel system[J]. Energy and Buildings, 2015,86:58-65.

[4] De Adana, Ruiz M, Olmedo, et al. Experimental Evaluation of the Thermal Comfort in an Occupied Office under Transient Conditions using a Hydronic Radiant Ceiling Cooling System[J]. ASHRAE Transactions, 2014,120.

[5] Kim M K, Leibundgut H. Evaluation of the humidity performance of a novel radiant cooling system connected with an Airbox convector as a low exergy system adapted to hot and humid climates[J]. Energy and Buildings, 2014,84:224-232.

[6] Teodosiu C, Ilie V, Teodosiu R. Numerical Prediction of Thermal Comfort and Condensation Risk in a Ventilated Office, Equipped with a Cooling Ceiling[J]. Energy Procedia, 2016,85:550-558.

[7] Oxizidis S, Papadopoulos A M. Performance of radiant cooling surfaces with respect to energy 
consumption and thermal comfort[J]. Energy \& Buildings, 2013,57.

[8] Imanari T, Omori T, Bogaki K. Thermal comfort and energy consumption of the radiant ceiling panel system.: Comparison with the conventional all-air system[J]. Energy and Buildings, 1999,30(2):167-175.

[9] Khan Y, Khare V R, Mathur J, et al. Performance evaluation of radiant cooling system integrated with air system under different operational strategies[J]. Energy and Buildings, 2015,97:118-128. 